\title{
Mental health problems in youths committed to juvenile institutions: prevalences and treatment needs
}

\author{
Ola Ståhlberg • Henrik Anckarsäter • \\ Thomas Nilsson
}

Received: 27 November 2009/ Accepted: 21 September 2010/Published online: 15 October 2010

(C) The Author(s) 2010. This article is published with open access at Springerlink.com

\begin{abstract}
Many international studies show that adolescents in coercive institutional care display high prevalences of mental disorders, especially in the form of disruptive behavior disorders [including attention-deficit/hyperactivity disorder (AD/HD), oppositional defiant disorder, and conduct disorder], anxiety disorders, and mood disorders. High degrees of overlap across mental disorders have also been reported. In addition, institutionalized adolescents are often traumatized. Despite this well-documented psychiatric morbidity, the mental health care needs of detained adolescents are often overlooked. The main objective of this study is to assess prevalences of psychiatric disorders, results of intelligence tests, and previous contacts with child and adolescent psychiatric services among adolescents in institutional care. DSM-IV diagnoses, mental health contacts, substance abuse, neurocognitive abilities, and school performance were registered in 100 adolescents ( 92 boys, 8 girls) aged $12-19$ years (mean age 16.0; $\mathrm{SD} \pm 1.5$ ) consecutively committed to Swedish juvenile institutions between 2004 and 2007. At least one psychiatric disorder was diagnosed in $73 \%$ of the subjects: $48 \%$ met DSM-IV diagnostic criteria for $\mathrm{AD} / \mathrm{HD}, 17 \%$ for an autism spectrum disorder, and $10 \%$ for a mental retardation. The collapsed prevalence for psychiatric disorders requiring specialist attention was $63 \%$. Our data indicate that systematic diagnostic procedures are crucial in the treatment planning for institutionalized adolescents.
\end{abstract}

O. Ståhlberg · H. Anckarsäter · T. Nilsson

Forensic Psychiatry, University of Lund, Lund, Sweden

O. Ståhlberg $(\bowtie) \cdot H$. Anckarsäter · T. Nilsson

Forensic Psychiatry, University of Gothenburg,

Gothenburg, Sweden

e-mail: ola.stahlberg@neuro.gu.se
Adequate treatment strategies need to be designed and implemented to meet the extensive mental health care needs of this vulnerable population.

Keywords Adolescent psychiatry - Mental health · Attention deficit disorder with hyperactivity .

Pervasive development disorders - Conduct disorder

\section{Introduction}

Many international studies report high prevalences of mental disorders among adolescents in coercive care. Teplin and coworkers [31] showed that almost two-thirds of male and three-quarters of female juvenile detainees fulfilled criteria for one or more mental disorders. Excluding conduct disorder (CD) as a tautological definition in research on the causes of institutional care since it is a direct description of the kind of behaviors that tend to warrant institutionalization, $60 \%$ of boys and $66 \%$ of girls still met the diagnostic criteria for at least one major psychiatric disorder. Studies from the United Kingdom have compared the prevalence of mental disorders among young people under care with adolescents in the general population and found a three to fivefold increase among the former [10, 23], with mental disorders significantly affecting at least one in two, and even higher rates among the subjects in residential care compared to those placed with foster carers or with their natural parents [23].

Teplin and coworkers [31] found the most common disorders among both boys and girls to be substance use disorders, disruptive behavior disorders [oppositional defiant disorder (ODD), and $\mathrm{CD}$ ], followed by anxiety disorders, mood disorders, and attention-deficit/hyperactivity disorder (AD/HD). A recent meta-analysis based 
on 25 studies mainly confirmed these findings and also found a tenfold increase in psychotic disorders among institutionalized adolescents compared to the overall population [12].

High degrees of overlap across mental disorders have also been reported among juvenile detainees. Abram and colleagues [2] showed that more than half of girls and almost half of boys fulfilled the criteria for two or more disorders (often including severe mental disorders and substance abuse in combination, sometimes referred to as "double diagnoses").

In a clinically based Swedish study, Anckarsäter and coworkers [7] showed that $53 \%$ of institutionalized adolescents fulfilled criteria for at least one neuropsychiatric disorder [defined as autism spectrum disorders (ASDs), $\mathrm{AD} / \mathrm{HD}$, tic disorder, mental retardation $(\mathrm{MR})$, and other learning disabilities]. AD/HD, affecting $39 \%$ of the adolescents, was the most common disorder. Moreover, $66 \%$ of the adolescents had a psychiatric disorder requiring specialist treatment (AD/HD, ASD, MR, complicated depression and/or psychoses).

Disruptive behavior disorders are conditions that not only severely affect children's general health and education [13] but also carry a dramatically increased risk for mental health problems, substance abuse, and criminality in adulthood [17, 21]. It is therefore of vital importance, both for those afflicted and for society at large, that the period when a troubled child is in institutional care (if not before) is used to identify health care needs and implement effective preventive and treatment programs to counteract the negative prognosis. One proposed risk indicator is the age at onset of CD and substance abuse [15, 25], with the most severe mental health problems and poorest prognosis in those with an early onset of CD (defined as pre-pubertal or before 10 years of age).

These circumstances illustrate the need for further studies with a broad diagnostic approach, and the present study was designed to explore findings from comprehensive neuropsychiatric and psychiatric assessments of subjects in Swedish juvenile institutions organized under the authority of the National Board of Institutional Care (SiS). The specific aims were: (a) to provide detailed data on the prevalence and constellation of mental health problems, operationally defined according to the DSM-IV [4] with special focus on AD/HD, ASDs, substance abuse, and CD (with early or late onset), (b) to describe the results of intelligence tests in different diagnostic subgroups, and (c) to quantify previous contacts with the child and adolescent psychiatric services in this group of institutionalized adolescents. A previously published study on similar groups [7] will be used for comparisons of prevalences and configurations of disorders.

\section{Subjects and methods}

Subjects

In Sweden, three different laws regulate the placement of adolescents in specialized SiS institutions:

1. Care of Young Persons (special provisions) Act (SFS 1990:52) [27] ("young persons act", referred to as "YPA"), a law applied if the adolescent, due to his/her behavior or environment, is at risk of coming to harm.

2. Care of Young Offenders Act (SFS 1998:60) [28] ("young offenders act", referred to as "YOA"), a law that allows courts of law to sentence offenders between the ages of criminal responsibility (15 years) and maturity (18 years) to incarceration in special youth institutions.

3. The Social Services Act (SFS 2001:453) [29], a law applied if the adolescent, due to his/her behavior or environment, is at risk of coming to harm and there is consensus between the authorities and the subject/ parents that treatment is needed.

During 2007, a total of 1,396 individuals (916 boys, 480 girls) were placed in specialized state-run institutions in Sweden: 1,242 (787 boys, 455 girls) of these according to the YPA, 81 (76 boys, 5 girls) according to the YOA, and 73 (53 boys, 20 girls) according to the Social Service Act. The total population in Sweden included 504,544 males and 477,990 females between the ages of 12 and 19 years, and about 1.25 per thousand adolescents per year were thus placed in institutions.

The present study group consisted of adolescents committed to specialized youth institutions in the southwest of Sweden between September 2004 and February 2007. Inclusion in the study required that the referring authorities, the court or the Social Services, had requested psychosocial and psychiatric assessments. Adolescents scheduled for no more than a short stay at the institutions due to emergency placements were excluded. Each subject gave his or her written consent to participate in the study. All nine juvenile SiS institutions in the Swedish region of Västra Götaland were invited to participate in the study. Two of the four institutions that accepted participation contributed 95 of a total of 103 consecutively committed adolescents meeting the inclusion criteria (rate of consent 92\%). The other two institutions contributed sporadic cases $(n=15)$, giving a total study group of 110 adolescents.

As only 3 of the 110 initially included subjects were committed according to the Social Services Act, these subjects were excluded from further analyses. Seven other subjects were excluded because of missing data. The final study group thus included 100 subjects with complete 
diagnostic records: 92 boys aged 12-19 (mean age 16.3; $\mathrm{SD} \pm 1.5$ ) and 8 girls aged 14-17 (mean age 15.1; SD \pm 1.1). Twenty-two subjects (all boys, mean age 17.6; $\mathrm{SD} \pm 0.7$, range $16-18$ ) were committed according to the YOA, while 78 subjects ( 70 boys, 8 girls, mean age 15.8; $\mathrm{SD} \pm 1.5$, range 12-19) were committed according to the YPA.

\section{Methods}

Based on the investigational proceedings normally followed at the studied institutions, clinical information was collected by teams consisting of psychologists, psychiatric social workers, and ward personnel on the regular staff and psychiatric specialists called in as consultants to conduct the medical investigations. The ratings were made by four specialists in psychiatry, eight psychologists, and three social workers. In addition, one of the authors (HA) was consulted in all complicated cases. He also scrutinized all medical files and made final decisions on the diagnostic work-up, when needed in consensus with the investigating teams. Three different study protocols were used: Protocols A, B, and C. Protocol A, containing demographic and other background information, included detailed data on school achievement, criminal history, substance abuse, family situation, ethnical origin, and was filled out by the social workers or, in a few cases, by the team psychologist. Protocol B, which contained data on neurocognitive function [i.e., the Wechsler Adult Intelligence Scale (WAIS) [34] or the Wechsler Intelligence Scale for Children (WISC) [33] test results] as well as information on personality factors, such as results on the Temperament and Character Inventory (TCI) [11], Junior Temperament and Character Inventory (J-TCI) [22], Beck Youth Inventories [9], The AutismTics, AD/HD and other Comorbidities inventory (A-TAC) [5], and Youth Self-Report (YSR) [3], was completed by the psychologist assigned to the case. The variation in instrumentation was due to the large age span among the subjects and to the fact that some of the instruments target only subpopulations in the study. Psychologists and/or social investigators rated 34 of the subjects with the Hare Psychopathy Checklist- Revised (PCL-R) [16], and 73 completed a self-rating questionnaire [Youth Psychopathic Inventory, YPI [8]] aimed at capturing psychopathic characteristics. Protocol C, which included structured checklists with DSM-IV criteria from the specialized psychiatric investigations was filled out by the consultant psychiatrist after discussions (and in consensus) with the investigation team. Based on the medical evaluation files, protocol $\mathrm{C}$ thus provided DSM-IV-based diagnostics for Axis I, including data on child neuropsychiatric conditions (AD/HD, ASD, tics and MR). Protocols A and C were completed for all subjects, while protocol B was incomplete in four cases.

Diagnostic algorithms defined for the pervasive developmental disorders (PDDs) in the DSM-IV were followed. In accordance with the most widely used clinical terminology, these disorders are referred to as ASDs, including autistic disorder (defined as fulfilling a total of at least six DSM-IV criteria distributed as at least two criteria under "impairment in social interaction" and at least one criterion under "impairment in communication" and at least one criterion under "restricted repetitive and stereotyped patterns of behavior, interests, and activities"), Asperger's disorder (defined as fulfilling at least two DSM-IV criteria under "impairment in social interaction" and at least one criterion under "restricted repetitive and stereotyped patterns of behavior, interests, and activities"), and PDD not otherwise specified (PDD NOS, defined as fulfilling at least three criteria distributed among any of the three DSM-IV autism areas). The ASDs were mutually exclusive and arranged in a hierarchical order where Asperger's disorder and PDD NOS were subordinated to autistic disorder and PDD NOS was subordinated to Asperger's disorder.

$\mathrm{AD} / \mathrm{HD}$ was classified into three subgroups according to the specifications in DSM-IV: (1) AD/HD predominantly inattentive type, ADD (defined as fulfilling at least six inattention DSM-IV criteria), (2) AD/HD predominantly hyperactive-impulsive type or hyperkinetic disorder (HD) (defined as fulfilling at least six hyperactivity-impulsivity DSM-IV criteria), and AD/HD combined type (defined as fulfilling at least six hyperactivity-impulsivity criteria and at least six inattention criteria). The $\mathrm{AD} / \mathrm{HD}$ subgroups were mutually exclusive.

For all other disorders, DSM-IV criteria limiting the possibility of assigning other comorbid psychiatric diagnoses were disregarded to allow comprehensive recording of the pattern of comorbidity. Systematic assessments of possible concomitant medical disorders, such as brain MRIs or chromosomal analyses, were not performed unless indicated by clinical findings.

The Wechsler Adult Intelligence Test III (WAIS-III) or the Wechsler Intelligence Scale for Children IV (WISC-IV) were used to assess the IQ and factor scores. WAIS-III was used in 58 and WISC-IV in 38 cases, 16 years or older for WAIS-III versus younger for WISC-IV. This means that $96 \%$ of all subjects had a test-based assessment of cognitive profiles. The full-scale IQ (FSIQ) could not be calculated in four subjects in whom all sub-tests were not administered, but $92 \%$ of all cases had a FSIQ determined by the Wechsler tests based on Swedish normative data provided by the publisher. In the statistical analyses, data from WAIS-III and WISC-IV were pooled to yield collapsed Wechsler scores. MR was defined as having a FSIQ equal to or below 70 . 


\section{Statistics}

To explore the differences between groups, non-parametric statistics were used [Chi-square test for independence (with Yates continuity correction), Mann-Whitney $U$-test]. Ninety-five percent confidence intervals and two-tailed $p$ values with a significance level set at the 5\% level ( $p \leq 0.05$ ) were used throughout the study. All calculations were made with the Statistical Package for the Social Sciences (SPSS) version 16.0.

\section{Results}

Seventy-three (73\%) subjects fulfilled the criteria for at least one major DSM-IV disorder, including ASD and AD/HD, but not counting CD and substance abuse. Table 1 and 2 present comprehensive figures of prevalences and patterns of overlap between disorders.

Almost half of the subjects had some form of AD/HD, with the combined type being the most frequent, followed by the inattentive and the hyperactive-impulsive types, respectively (see Table 1 for a detailed presentation). Overall, one subject in six met the criteria for an ASD, most often in the form of PDD NOS (primarily by fulfilling criteria within the "impairment in social interaction" area, a domain where $100 \%$ of all subjects with an ASD met at least one criterion, see Table 1 for a detailed presentation).

There were significantly more cases with AD/HD in the YPA than in the YOA group, 58\% versus 9\% $\left[\chi^{2}(d f=1\right.$, $n=100)=14.38, \quad p<0.001, \phi=0.403]$. Prevalences for ASDs and AD/HD were similar among boys and girls.

Eleven subjects (11\%) had both an ASD and AD/HD, which means that $65 \%$ of the subjects with ASD had comorbid $\mathrm{AD} / \mathrm{HD}$, and that $23 \%$ of those with $\mathrm{AD} / \mathrm{HD}$ had comorbid ASD. Overlaps between diagnoses are shown in Table 2.

Seventy-seven subjects $(77 \%)$ fulfilled the criteria for CD. The onset was reported as "late" (after 10 years of age) in 66 cases $(86 \%)$ and as "early" (before 10 years of age) in $11(14 \%)$. Patterns of psychiatric disorders in these groups are described in Table 2. There were no significant associations (by Chi-square test for independency, with Yates Continuity Correction-data provided by the author upon request) between $\mathrm{CD}$ vs no $\mathrm{CD}$ and $\mathrm{AD} / \mathrm{HD}$, ASD, sex, or legal category (YPA or YOA). Likewise, there was no significant association between early vs late onset of $C D$ and ASD, AD/HD, sex, or legal category.

Fifty-five $(55 \%)$ of all subjects had some kind of substance abuse (including alcohol). There was no significant association between $\mathrm{CD}$ and substance abuse (Chi-square test as previously).
The mean FSIQ in the study group was 85.3 (SD \pm 14.3, range 45-121), i.e., almost exactly one standard deviation below the population mean. The corresponding figures for boys $(n=92)$ and girls $(n=8)$ were 85.7 $(\mathrm{SD} \pm 14.2$, range $45-121)$ and $80.9(\mathrm{SD} \pm 16.1$, range 54-106), respectively, showing no significant sex difference in FSIQ $(U=270.0, z=-0.915, p=0.360)$. In the YPA group $(n=78)$ and the YOA group $(n=22)$, the mean FSIQ figures were 83.7 (SD \pm 14.3 , range 45-121) and 92.1 (SD \pm 12.7 , range 71-114), respectively. This difference was statistically significant $(U=421.0, z=$ $-2.180, p=0.029)$. Eleven subjects $(11 \%)$ had a FSIQ equal to or below 70, meeting the criteria for MR, and 30 subjects $(30 \%)$ fulfilled the criteria for DSM-IV borderline intellectual functioning (FSIQ $=71-84)$. The AD/HD group $(n=46)$ had a mean FSIQ of 81.8 (SD \pm 13.6 , range 45-121), which was significantly lower than the mean FSIQ of 88.7 (SD \pm 14.4 , range 53-114) in the group without $\mathrm{AD} / \mathrm{HD}(n=46)(U=711.0, z=-2.712$, $p=0.007)$. In the group with ASD $(n=17)$, the mean FSIQ was 84.4 (SD \pm 15.6 , range $45-113)$, and the subjects with ASD did not differ from those without ASD $(n=75)$, whose mean FSIQ was 85.5 (SD \pm 14.1 , range 47-121).

Besides the differences seen in FSIQ, only a few differences between diagnostic groups were noted in the factors [Verbal IQ (VIQ) and Performance IQ (PIQ)] and the four secondary indices [Verbal Comprehension Index (VCI), Perceptual Reasoning Index (PRI), Working Memory Index (WMI), and Processing Speed Index (PSI)] of the Wechsler scales. The groups with ADD, AD/HD combined form, and any form of AD/HD had significantly lower WMI than the group without AD/HD $(U=121.5$, $z=-2.13, p=0.033 ; U=339.5, z=-3.883, p=<0.001$ and $U=535.5, z=-3.729, p=<0.001$, respectively). The groups with AD/HD combined form or any form of $\mathrm{AD} / \mathrm{HD}$ also had significantly lower FSIQ $(U=493.5$, $z=-2.642, p=0.008$ and $U=711.0, z=-2.712, p=$ 0.007 , respectively) and VIQ $(U=495.0, z=-2.743$, $p=0.006$ and $U=764.5, z=-2.433, p=0.015$, respectively). AD/HD, regardless of subtype, was thus associated with significantly lower FSIQ, VIQ, and WMI. Among the groups with different forms of ASD no significant differences were found between the factors or indices. The YOA group scored significant higher than the YPA group in FSIQ, PIQ, PRI, and WMI $(U=421.0$, $z=-2.180, \quad p=0.029 ; \quad U=499.5, \quad z=-2.007, \quad p=$ 0.045; $U=398.0, z=-2.413, p=0.016$ and $U=330.0$, $z=-2.201, p=0.028$, respectively). The same pattern was found between FSIQ, VIQ, VCI, WMI, and PSI in the group with and the group without substance abuse $(U=$ 557.5, $z=-2.342, p=0.019 ; U=580.5, z=-2.318$, 


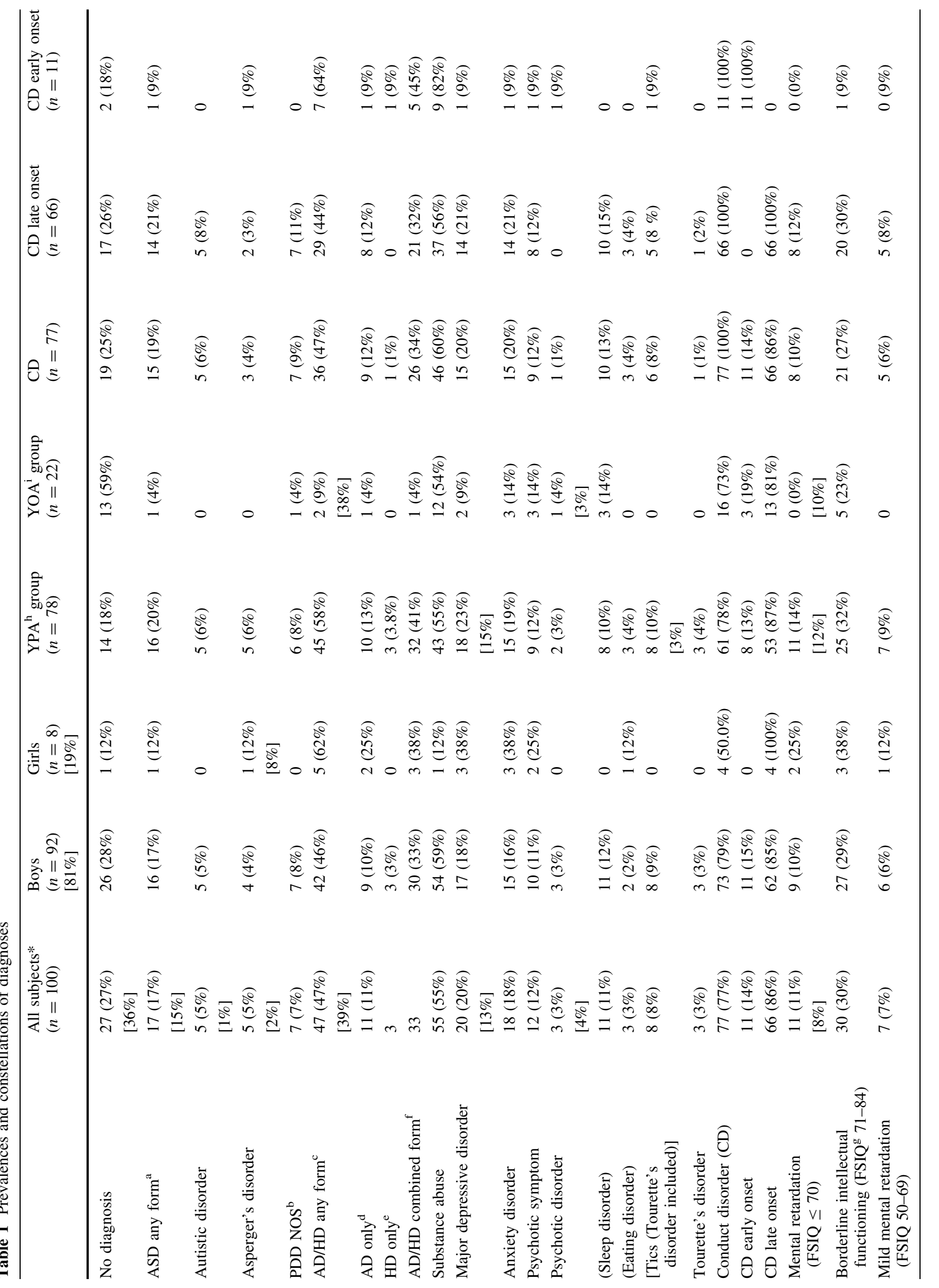




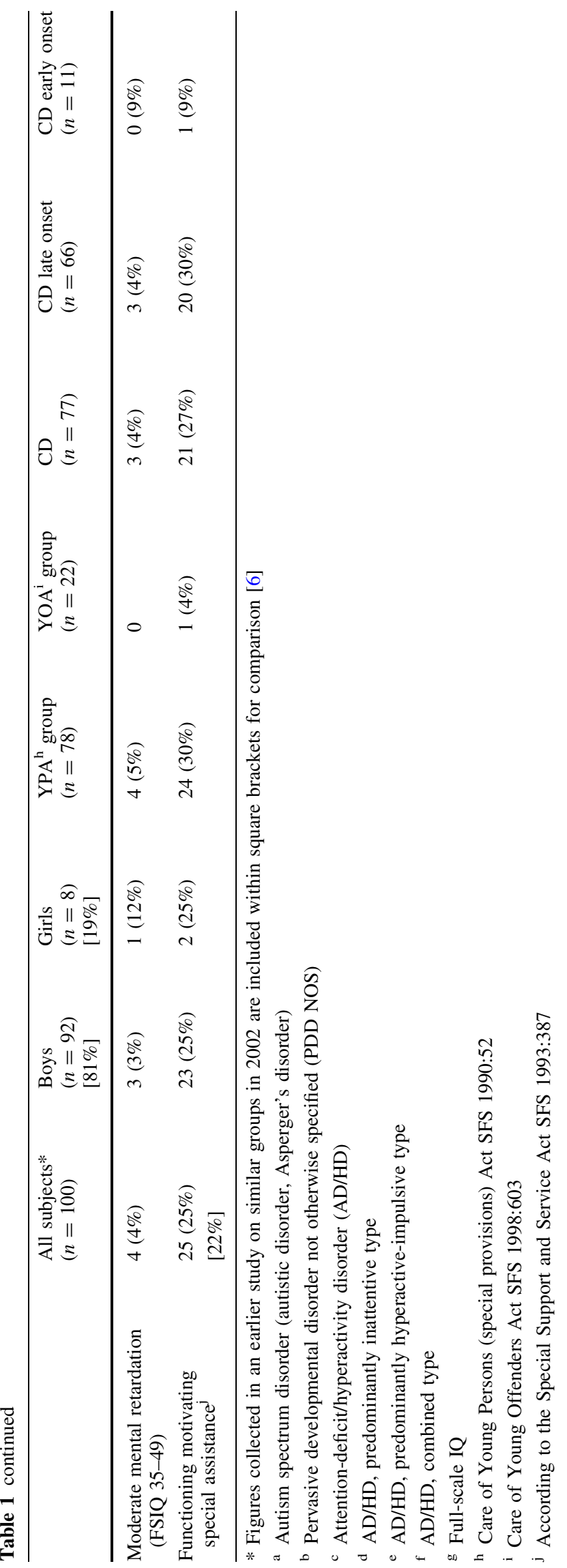

$p=0.020 ; U=601.0, z=-2.014, p=0.044 ; U=521.0$, $z=-2.279, \quad p=0.023$ and $U=555.0, \quad z=-2.558$, $p=0.011$, respectively). There were no significant differences in any factor or index between subjects with lateonset CD and early-onset CD (Table 3).

Overall, more than one in four $(27 \%)$ of the subjects had a severe mental disorder (ASD, MR, and/or psychotic disorder), which according to the Swedish legislation (the Special Support and Service Act SFS 1993:387) would make them entitled to special assistance. The overall proportion of individuals in need of psychiatric specialist treatment (AD/HD, ASD, MR, psychotic disorder, and/or complicated depression) was $63 \%$. In addition to these problems, a few subjects fulfilled criteria for sleep disorder, eating disorder, and/or tics (Table 1).

Regardless of diagnosis, substance use, and neurocognitive function, almost all subjects $(97 \%)$ reported major difficulties in school, most often in the form of truancy, bullying, learning problems, and special tuition and supervision (Table 4).

More than half of the subjects had been in contact with child and adolescent psychiatric services (CAP) at least once before admittance to the institution, and more than one-third of these more than once. One in five had been in contact with CAP within a period of one year prior to the index referral to the youth institution. Eighty-eight percent of the subjects with ASD had been in contact with CAP at least once, and the corresponding figures for subjects with $\mathrm{AD} / \mathrm{HD}, \mathrm{MR}$, and $\mathrm{CD}$ was 70,54 , and $52 \%$, respectively. The important message conveyed by these figures is that considerable numbers of children with severe mental problems, including as many as half of those with MR, had not come to the attention of the CAP services before being committed to specialized institutions (Table 4 gives a thorough presentation of CAP contacts in the various diagnostic groups).

\section{Discussion}

Overall, $63 \%$ of the adolescents in the studied youth institutions had a psychiatric disorder generally considered to require specialist attention. More than one in four, $27 \%$, had a psychotic disorder or a neurocognitive disability (ASD and/or MR) severe enough to entitle to special rights to assistance according to the Swedish legislation. These figures are generally consistent with the results of other surveys [23, 26, 31, 32] and exceed by far the figures found for comparable normal populations [10, 18, 23]. In a total population study of young schoolchildren from a middlesized Swedish town, clinically severely impairing AD/HD was found in $3.7 \%$ and autism and Asperger's disorder in another $1.1 \%$ [18]. The rate of ASD in the general 


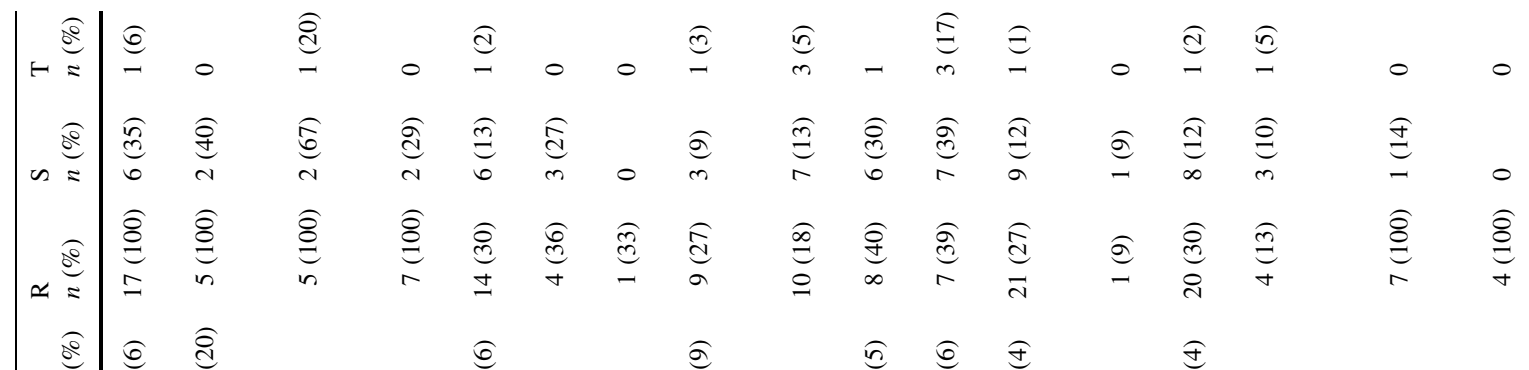

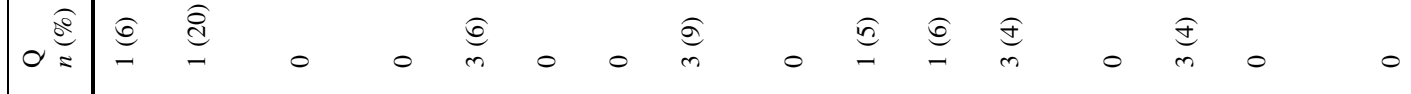

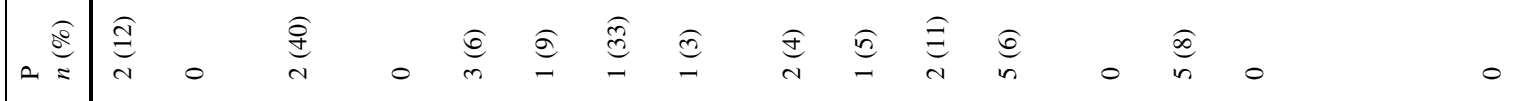

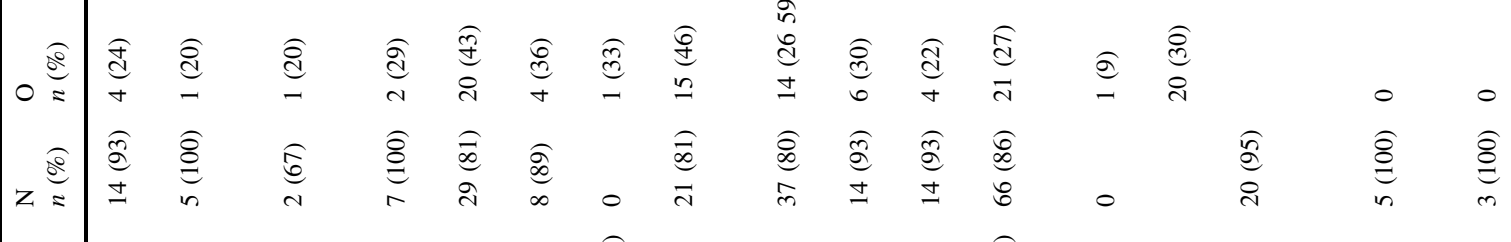

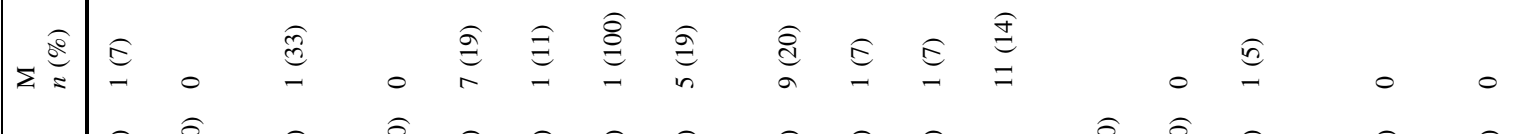

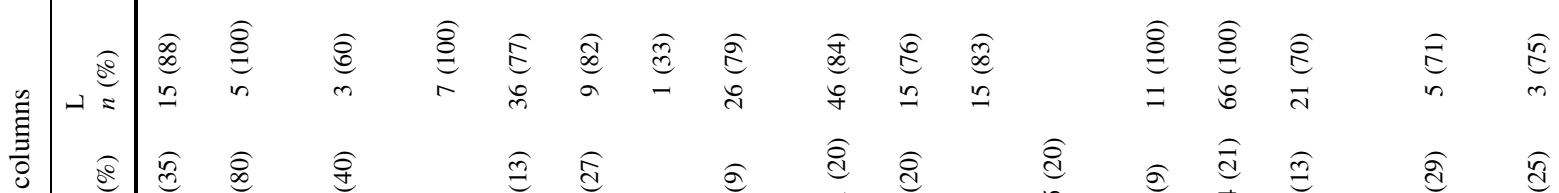

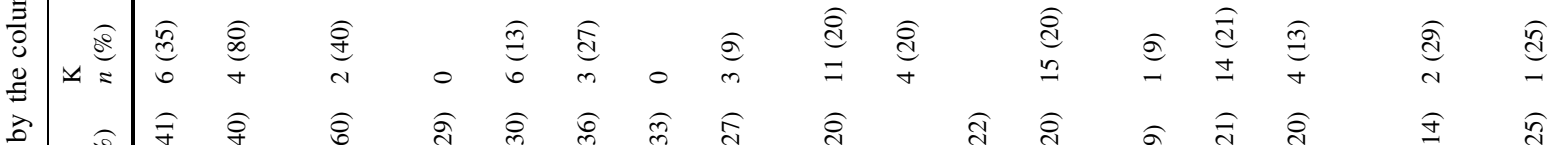

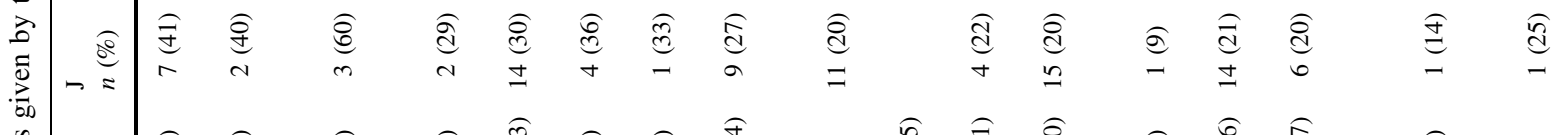

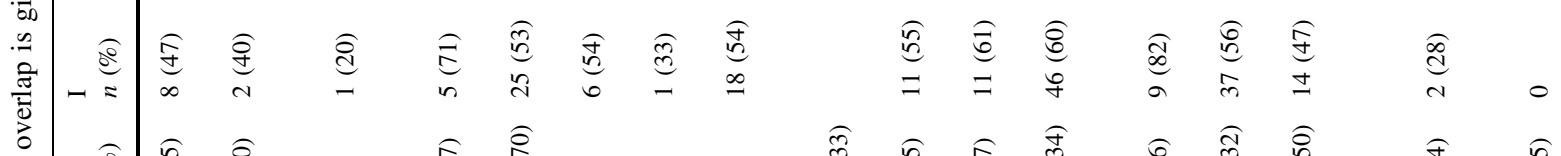

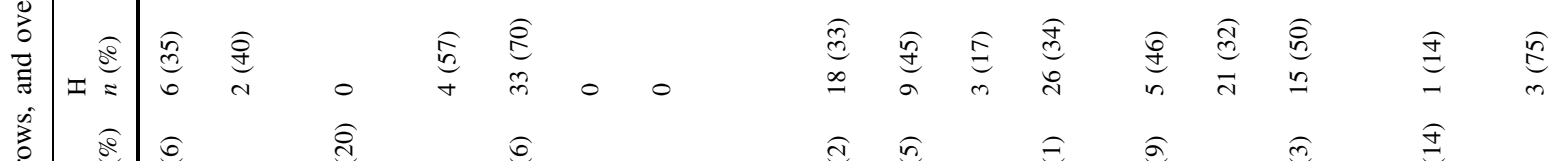

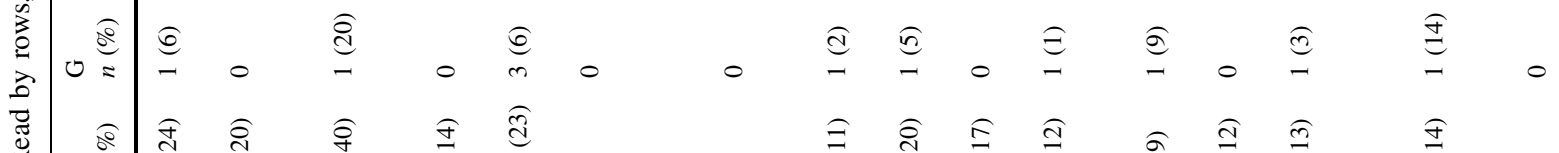

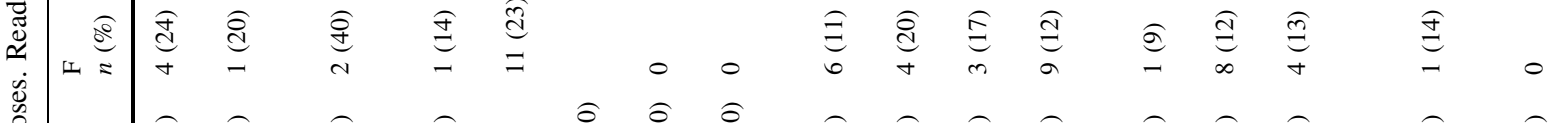

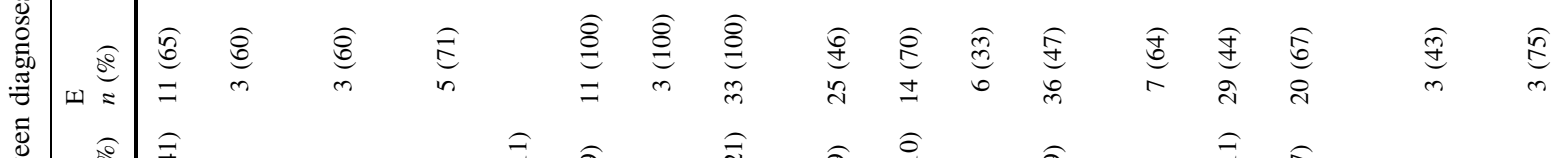

$$
\begin{aligned}
& \text { 离 }
\end{aligned}
$$

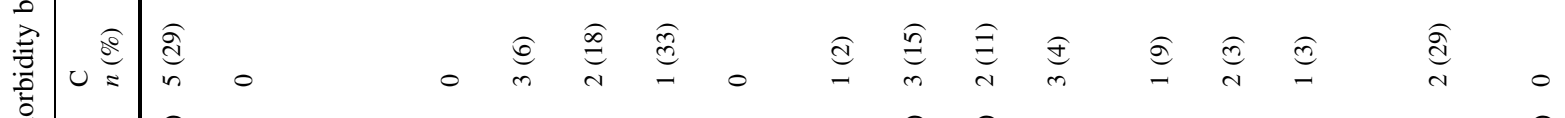

$$
\begin{aligned}
& \text { 苛 }
\end{aligned}
$$

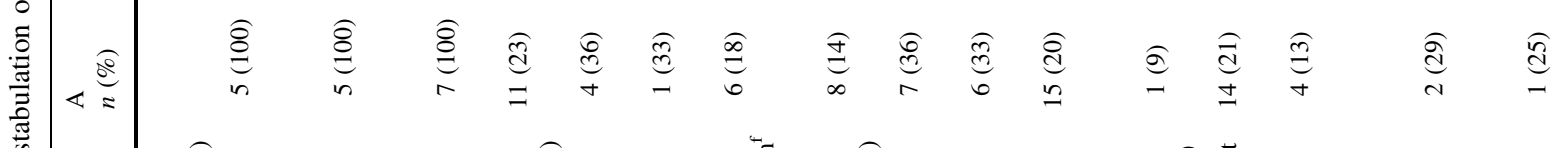

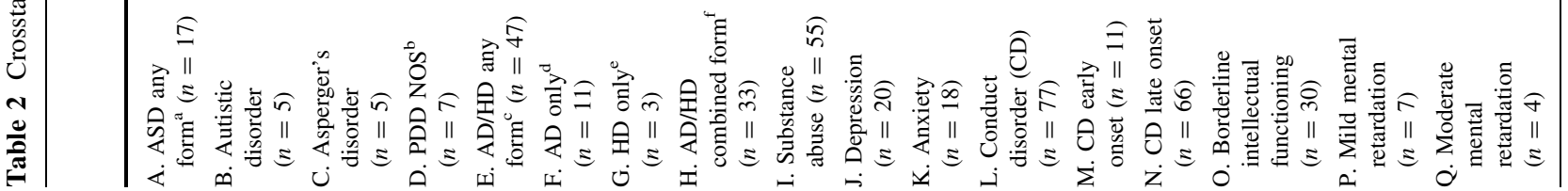




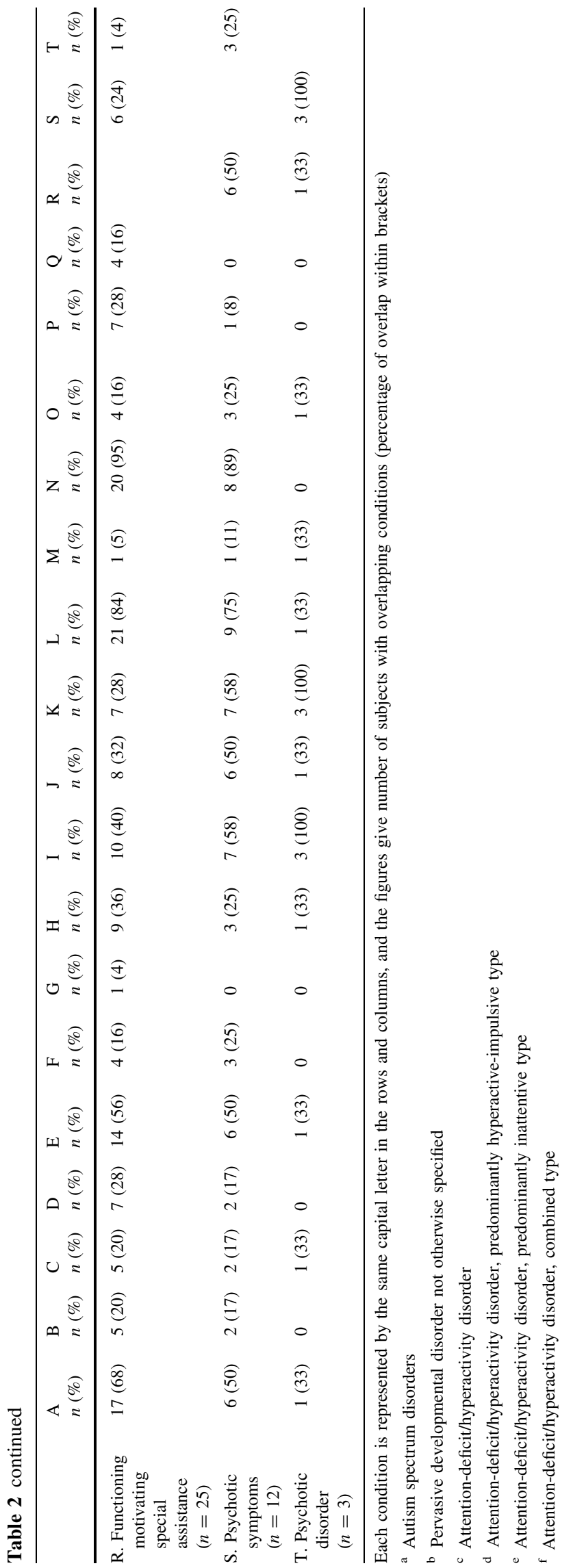

population was found to be $1.2 \%$ [20], which was in line with the range reported in other countries. That the general population figures are about ten times lower than the prevalences in our sample signals a considerable overrepresentation of severe mental health problems among institutionalized adolescents in Sweden. The diagnostic panorama seems to vary considerably across studies, however, depending on the criteria or terminology used. Special assessments for ASDs seem to be rare in surveys outside Scandinavia and the UK, where, in contrast, considerable prevalences of especially PDD NOS/atypical autism are consistently reported. Assessments have to target not only narrow syndromes among the ASDs but also the atypical forms or even broader phenotypes in future studies of mental health problems among adolescents referred to specialized institutions in order to capture adolescents with severe social dysfunctions on the autism spectrum [6].

The majority of adolescents with diagnoses of mental disorder fulfilled criteria for more than one such disorder. This was especially the case when the primary disorder was in the category describing neurocognitive problems, such as ASDs, MR, and/or AD/HD. The high degree of comorbidity corresponds to findings from other studies [19, 30], and may imply a broad range of still unresolved treatment problems [14]. Institutions for adolescents like those we investigated clearly need access not only to medical support but also to professionals especially trained in child and adolescent psychiatry and neuropsychiatry to provide diagnostic evaluations, neurological examinations, and pharmacological treatment both of common disorders, such as $\mathrm{AD} / \mathrm{HD}$, and rare conditions, such as autism, tic disorders, and various subtypes of MR.

Criteria for ASDs have to be adapted to adolescents in institutions, where social interaction problems and nonverbal communication abnormalities stand out as the hallmarks of the disorder, whereas classical Aspergerassociated, fact-based special interests or elaborate repetitive routines are rare. Stereotyped behaviors may instead be found in repetitive crime patterns, collections of knives or other criminal paraphernalia, or a strong interest in drugs without indications of substance use disorders. A pervasive inability to take other people's perspectives and social "oddity", even when compared to other adolescents with similar lifestyles, are also recurrent features in ASD.

We found no support for the hypothesis that age of onset of $\mathrm{CD}$ would distinguish between clinical subgroups (with more severe problems corresponding to early-onset $\mathrm{CD}$ ). One possible reason for this disagreement with previous findings [25] may be lack of reliable information regarding time of onset of conduct problems in our subjects. Another explanation may be that the relevance of time of onset is obscured by the complex pattern of associated problems in this heavily affected group. If so, the age at onset of CD may 
Table 3 Distribution of full-scale IQ (FSIQ), Verbal IQ (VIQ), Performance IQ (PIQ), Verbal comprehension index (VCI), Perceptual reasoning index (PRI), Working memory index (WMI), and Processing speed index (PSI) among different diagnoses

\begin{tabular}{|c|c|c|c|c|c|c|c|}
\hline & $\begin{array}{l}\text { Mean FSIQ } \\
( \pm \text { SD })\end{array}$ & $\begin{array}{l}\text { Mean VIQ } \\
( \pm \text { SD })\end{array}$ & $\begin{array}{l}\text { Mean PIQ } \\
( \pm \mathrm{SD})\end{array}$ & $\begin{array}{l}\text { Mean VCI } \\
( \pm \text { SD })\end{array}$ & $\begin{array}{l}\text { Mean PRI } \\
( \pm \mathrm{SD})\end{array}$ & $\begin{array}{l}\text { Mean WMI } \\
( \pm \text { SD })\end{array}$ & $\begin{array}{l}\text { Mean PSI } \\
( \pm \text { SD })\end{array}$ \\
\hline All subjects $(n=100)$ & $\begin{array}{l}85.3(14.3) \\
(n=92)\end{array}$ & $\begin{array}{l}86.8(13.8) \\
(n=93)\end{array}$ & $\begin{array}{l}86.6(15.4) \\
(n=94)\end{array}$ & $\begin{array}{l}87.0(14.0) \\
(n=92)\end{array}$ & $\begin{array}{l}91.2(16.3) \\
(n=92)\end{array}$ & $\begin{array}{l}87.0(12.6) \\
(n=89)\end{array}$ & $\begin{array}{l}85.0(12.5) \\
(n=93)\end{array}$ \\
\hline Boys $(n=92)$ & $\begin{array}{l}85.7(14.2) \\
(n=84)\end{array}$ & $\begin{array}{l}87.6(13.6) \\
(n=85)\end{array}$ & $\begin{array}{l}86.5(15.4) \\
(n=86)\end{array}$ & $\begin{array}{l}87.7(13.8) \\
(n=84)\end{array}$ & $\begin{array}{l}91.3(16.4) \\
(n=84)\end{array}$ & $\begin{array}{l}87.6(12.8) \\
(n=81)\end{array}$ & $\begin{array}{l}85.1(12.5) \\
(n=85)\end{array}$ \\
\hline Girls $(n=8)$ & $\begin{array}{l}80.9(16.1) \\
(n=8)\end{array}$ & $\begin{array}{l}78.8(14.5) \\
(n=8)\end{array}$ & $\begin{array}{l}88.0(15.7) \\
(n=8)\end{array}$ & $\begin{array}{l}80.0(14.7) \\
(n=8)\end{array}$ & $\begin{array}{l}90.8(15.6) \\
(n=8)\end{array}$ & $\begin{array}{l}83.1(9.9) \\
(n=8)\end{array}$ & $\begin{array}{l}83.1(13.3) \\
(n=8)\end{array}$ \\
\hline YOA $^{\mathrm{a}}$ group $(n=22)$ & $\begin{array}{l}92.1(12.7) \\
(n=17)\end{array}$ & $\begin{array}{l}92.0(11.2) \\
(n=18)\end{array}$ & $\begin{array}{l}93.6(13.3) \\
(n=19)\end{array}$ & $\begin{array}{l}90.4(10.3) \\
(n=17)\end{array}$ & $\begin{array}{l}100.0(12.4) \\
(n=17)\end{array}$ & $\begin{array}{l}95.9(15.3) \\
(n=14)\end{array}$ & $\begin{array}{l}85.6(10.1) \\
(n=19)\end{array}$ \\
\hline YPA $^{\mathrm{b}}$ group $(n=78)$ & $\begin{array}{l}83.7(14.3) \\
(n=75)\end{array}$ & $\begin{array}{l}85.6(14.1) \\
(n=75)\end{array}$ & $\begin{array}{l}84.9(15.4) \\
(n=75)\end{array}$ & $\begin{array}{l}86.3(14.7) \\
(n=75)\end{array}$ & $\begin{array}{l}89.3(16.5) \\
(n=75)\end{array}$ & $\begin{array}{l}85.6(11.4) \\
(n=75)\end{array}$ & $\begin{array}{l}84.8(13.1) \\
(n=74)\end{array}$ \\
\hline ASD any form ${ }^{\mathrm{c}}(n=17)$ & $\begin{array}{l}84.4(15.6) \\
(n=17)\end{array}$ & $\begin{array}{l}87.9(15.9) \\
(n=17)\end{array}$ & $\begin{array}{l}83.4(14.5) \\
(n=17)\end{array}$ & $\begin{array}{l}89.4(16.1) \\
(n=17)\end{array}$ & $\begin{array}{l}87.3(17.2) \\
(n=17)\end{array}$ & $\begin{array}{l}85.8(9.7) \\
(n=17)\end{array}$ & $\begin{array}{l}87.2(8.8) \\
(n=16)\end{array}$ \\
\hline AD/HD any type ${ }^{\mathrm{d}}(n=47)$ & $\begin{array}{l}81.8(13.6) \\
(n=46)\end{array}$ & $\begin{array}{l}83.5(13.8) \\
(n=46)\end{array}$ & $\begin{array}{l}83.5(14.8) \\
(n=46)\end{array}$ & $\begin{array}{l}84.8(14.0) \\
(n=46)\end{array}$ & $\begin{array}{l}88.0(16.2) \\
(n=46)\end{array}$ & $\begin{array}{l}82.5(10.3) \\
(n=46)\end{array}$ & $\begin{array}{l}84.8(13.0) \\
(n=45)\end{array}$ \\
\hline Drug abuse $(n=55)$ & $\begin{array}{l}88.7(12.0) \\
(n=52)\end{array}$ & $\begin{array}{l}90.0(12.8) \\
(n=52)\end{array}$ & $\begin{array}{l}89.3(12.3) \\
(n=52)\end{array}$ & $\begin{array}{l}90.4(13.0) \\
(n=51)\end{array}$ & $\begin{array}{l}94.1(12.5) \\
(n=51)\end{array}$ & $\begin{array}{l}88.9(12.2) \\
(n=50)\end{array}$ & $\begin{array}{l}87.8(10.9) \\
(n=52)\end{array}$ \\
\hline Depression $(n=20)$ & $\begin{array}{l}85.0(12.1) \\
(n=20)\end{array}$ & $\begin{array}{l}86.3(12.4) \\
(n=20)\end{array}$ & $\begin{array}{l}86.6(13.4) \\
(n=20)\end{array}$ & $\begin{array}{l}86.2(11.7) \\
(n=20)\end{array}$ & $\begin{array}{l}91.2(15.5) \\
(n=20)\end{array}$ & $\begin{array}{l}86.5(11.0) \\
(n=19)\end{array}$ & $\begin{array}{l}84.5(11.7) \\
(n=20)\end{array}$ \\
\hline Anxiety disorder $(n=18)$ & $\begin{array}{l}84.9(16.0) \\
(n=17)\end{array}$ & $\begin{array}{l}86.4(17.2) \\
(n=17)\end{array}$ & $\begin{array}{l}86.7(11.9) \\
(n=17)\end{array}$ & $\begin{array}{l}87.5(17.9) \\
(n=17)\end{array}$ & $\begin{array}{l}91.3(14.0) \\
(n=17)\end{array}$ & $\begin{array}{l}87.6(10.2) \\
(n=17)\end{array}$ & $\begin{array}{l}85.5(10.4) \\
(n=16)\end{array}$ \\
\hline Conduct disorder (CD) $(n=77)$ & $\begin{array}{l}85.9(14.1) \\
(n=74)\end{array}$ & $\begin{array}{l}87.2(13.7) \\
(n=7)\end{array}$ & $\begin{array}{l}87.2(13.6) \\
(n=75)\end{array}$ & $\begin{array}{l}87.6(14.0) \\
(n=74)\end{array}$ & $\begin{array}{l}92.6(15.1) \\
(n=74)\end{array}$ & $\begin{array}{l}87.4(11.4) \\
(n=71)\end{array}$ & $\begin{array}{l}85.0(11.0) \\
(n=74)\end{array}$ \\
\hline Psychotic symptoms $(n=12)$ & $\begin{array}{l}87.3(13.5) \\
(n=11)\end{array}$ & $\begin{array}{l}88.8(14.7) \\
(n=11)\end{array}$ & $\begin{array}{l}88.1(11.4) \\
(n=11)\end{array}$ & $\begin{array}{l}91.7(15.6) \\
(n=10)\end{array}$ & $\begin{array}{l}94.6(11.2) \\
(n=10)\end{array}$ & $\begin{array}{l}87.3(10.4) \\
(n=10)\end{array}$ & $\begin{array}{l}82.7(11.8) \\
(n=11)\end{array}$ \\
\hline $\begin{array}{l}\text { Mental retardation } \\
\quad(\text { FSIQ } \leq 70)(n=11)\end{array}$ & $\begin{array}{l}59.4(8.8) \\
(n=11)\end{array}$ & $\begin{array}{l}67.1(12.3) \\
(n=11)\end{array}$ & $\begin{array}{l}60.5(11.2) \\
(n=11)\end{array}$ & $\begin{array}{l}68.2(11.8) \\
(n=11)\end{array}$ & $\begin{array}{l}63.0(10.0) \\
(n=11)\end{array}$ & $\begin{array}{l}83.6(12.0) \\
(n=11)\end{array}$ & $\begin{array}{l}70.8(15.1) \\
(n=10)\end{array}$ \\
\hline $\begin{array}{l}\text { Borderline intellectual } \\
\text { functioning (FSIQ 71-84) }(n=30)\end{array}$ & $\begin{array}{l}77.8(4.2) \\
(n=30)\end{array}$ & $\begin{array}{l}79.9(9.7) \\
(n=30)\end{array}$ & $\begin{array}{l}80.1(9.2) \\
(n=30)\end{array}$ & $\begin{array}{l}80.1(10.9) \\
(n=29)\end{array}$ & $\begin{array}{l}84.6(10.0) \\
(n=29)\end{array}$ & $\begin{array}{l}79.2(10.5) \\
(n=29)\end{array}$ & $\begin{array}{l}81.2(13.1) \\
(n=30)\end{array}$ \\
\hline $\begin{array}{l}\text { Functioning motivating special } \\
\text { assistance }^{\mathrm{e}}(n=25)\end{array}$ & $\begin{array}{l}76.2(18.1) \\
(n=25)\end{array}$ & $\begin{array}{l}80.9(17.1) \\
(n=25)\end{array}$ & $\begin{array}{l}76.0(17.1) \\
(n=25)\end{array}$ & $\begin{array}{l}81.9(17.6) \\
(n=25)\end{array}$ & $\begin{array}{l}79.8(18.5) \\
(n=25)\end{array}$ & $\begin{array}{l}85.5(10.4) \\
(n=25)\end{array}$ & $\begin{array}{l}81.3(14.4) \\
(n=24)\end{array}$ \\
\hline
\end{tabular}

${ }^{a}$ Care of Young Offenders Act SFS 1998:603

b Care of Young Persons (special provisions) Act SFS 1990:52

c Autism spectrum disorder (autistic disorder, Asperger's disorder, pervasive developmental disorder not otherwise specified)

d Attention-deficit/hyperactivity disorder (AD/HD) (AD/HD predominantly inattentive type, AD/HD predominantly hyperactive-impulsive type or attention-deficit/hyperactivity disorder, combined type)

e According to the Special Support and Service Act SFS 1993:387

be a marker of especially problematic cases in the general population, which loses its predictive power in groups enriched by severe problems from onset, such as ours.

In line with studies of adolescents mental health service use $[1,24]$ the subjects in this study showed the same pattern in regards to contact with child and adolescent psychiatric health service characterized by an unbalance between need and use. Not surprisingly it was the adolescents with substance abuse problems, CD and MR who had the least extensive mental health service use. Almost all of the subjects had showed, and in most cases still show, severe school related problems. In the light of the high prevalence of $\mathrm{CD}$ and $\mathrm{AD} / \mathrm{HD}$, this is of course not surprisingly, but also shows the urgent need for developing special educational programs for adolescents with these kinds of problems.

The current literature and our own studies demonstrate that there is a need to include care and treatment programs based on neuropsychiatric knowledge along with the traditional psychosocial support programs provided in special youth institutions. The low level of use of mental health services despite the extensive needs in this group clearly call for the establishment of a closer collaboration with the 
Table 4 Patterns of child and adolescent psychiatric (CAP) contacts, school problems, and substance abuse among different groups

\begin{tabular}{|c|c|c|c|}
\hline & $\begin{array}{l}\text { Number of subjects with } \\
\text { CAP contact ever in life } \\
n(\%)\end{array}$ & $\begin{array}{l}\text { School } \\
\text { problems } \\
n(\%)\end{array}$ & $\begin{array}{l}\text { Substance } \\
\text { abuse } \\
n(\%)\end{array}$ \\
\hline All subjects $(n=100)$ & $53(53)$ & $96(96)$ & $55(55)$ \\
\hline Boys $(n=92)$ & $47(51)$ & $88(96)$ & $54(59)$ \\
\hline Girls $(n=8)$ & $6(75)$ & $8(100)$ & $1(12)$ \\
\hline 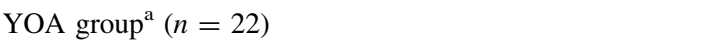 & $5(23)$ & $20(91)$ & $12(54)$ \\
\hline 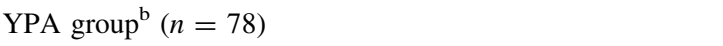 & $48(62)$ & $76(97)$ & $43(55)$ \\
\hline ASD any form ${ }^{\mathrm{c}}(n=17)$ & $15(88)$ & $16(94)$ & $8(47)$ \\
\hline AD/HD any type ${ }^{\mathrm{d}}(n=47)$ & $33(70)$ & $46(98)$ & $25(53)$ \\
\hline Substance abuse $(n=55)$ & $28(51)$ & $53(96)$ & $55(100)$ \\
\hline Depression $(n=20)$ & $13(65)$ & $20(100)$ & $18(90)$ \\
\hline Anxiety disorder $(n=18)$ & $13(72)$ & $18(100)$ & $11(61)$ \\
\hline Conduct disorder (CD) $(n=77)$ & $40(52)$ & $77(100)$ & $46(60)$ \\
\hline Psychotic symptoms $(n=12)$ & $9(75)$ & $12(100)$ & $7(58)$ \\
\hline Mental retardation $(\mathrm{FSIQ} \leq 70)(n=11)$ & $6(54)$ & $9(82)$ & $2(18)$ \\
\hline Borderline intellectual functioning (FSIQ 71-84) $(n=30)$ & $17(57)$ & $30(100)$ & $14(47)$ \\
\hline Functioning motivating special assistance ${ }^{\mathrm{e}}(n=25)$ & $18(72)$ & $23(92)$ & $10(40)$ \\
\hline
\end{tabular}

${ }^{a}$ Care of Young Offenders Act SFS 1998:603

${ }^{\mathrm{b}}$ Care of Young Persons (special provisions) Act SFS 1990:52

c Autism spectrum disorder (autistic disorder, Asperger's disorder or pervasive developmental disorder not otherwise specified)

d Attention-deficit/hyperactivity disorder (AD/HD) (AD/HD predominantly inattentive type, AD/HD predominantly hyperactive-impulsive type or attention-deficit/hyperactivity disorder, combined type)

e According to the Special Support and Service Act SFS 1993:387

child and adolescent mental health services in order to ascertain that adolescents committed to institutions receive appropriate treatment.

Acknowledgments This work was supported by grants to HA from The National Board of Institutional Care (SiS), Sweden, to TN from the National Board of Forensic Medicine, and by support to OS from the Region of Västra Götaland. The following clinical psychologists, psychiatrists, and social workers are highly appreciated for their contributions to the collection of clinical data: Iraj Abedini, Agneta Andersson, Susanne Durehed, Anders Elverfors, Anders W Eriksson, Mats Gustafsson, Eva Hallberg, Sabina Johansson, Mats Johnson, Peter Sand, Dan Sjöholm, and Elisabet Åkerlund. Monika Montell and Agneta Brimse were excellent research secretaries.

\section{Conflict of interest None.}

Open Access This article is distributed under the terms of the Creative Commons Attribution Noncommercial License which permits any noncommercial use, distribution, and reproduction in any medium, provided the original author(s) and source are credited.

\section{References}

1. Abram KM, Paskar LD, Washburn JJ, Teplin LA (2008) Perceived barriers to mental health services among youths in detention. J Am Acad Child Adolesc Psychiatry 47:301-308
2. Abram KM, Teplin LA, McClelland GM, Dulcan MK (2003) Comorbid psychiatric disorders in youth in juvenile detention. Arch Gen Psychiatry 60:1097-1108

3. Achenbach TM, Rescorla LA (2001) Manual for the ASEBA school-age forms \& profiles. University of Vermont, Research center for children, youth, and families, Burlington

4. American Psychiatric Association (1994) Diagnostic and statistical manual of mental disorders : DSM-IV. American Psychiatric Association, Washington, DC

5. Anckarsater H, Lichtenstein P, Carlström E, Stahlberg O, Gillberg C (2007) Psychometric development of the Autism-Tics, $\mathrm{AD} / \mathrm{HD}$ and other Comorbidities (A-TAC) inventory. Full version with gate structure; based on clinic and general population. http://www.childnps.se

6. Anckarsater H, Nilsson T, Saury JM, Rastam M, Gillberg C (2008) Autism spectrum disorders in institutionalized subjects. Nord J Psychiatry 62:160-167

7. Anckarsäter H, Nilsson T, Stahlberg O, Gustafson M, Saury JM, Rastam M, Gillberg C (2007) Prevalences and configurations of mental disorders among institutionalized adolescents. Dev Neurorehabil 10:57-65

8. Andershed H, Kerr M, Stattin H, Levander S (2002) Psychopathic traits in non-referred youths: initial test of a new assessment tool. In: Blaauw E, Sheridan L (eds) Psychopaths: current international perspectives. Elsevier, The Hague, pp 131-158

9. Beck AT, Beck JS, Jolly J (2001) Beck youth inventories of emotional \& social impairment manual. Psychological Corporation, San Antonio

10. Buchanan A (1999) The mental health of children who are looked after. In: Wheal A (ed) The companion to foster care. Russel House Publishing, Lyme Regis, pp 179-205 
11. Cloninger CR, Svrakic DM, Przybeck TR (1993) A psychobiological model of temperament and character. Arch Gen Psychiatry 50:975-990

12. Fazel S, Doll H, Langstrom N (2008) Mental disorders among adolescents in juvenile detention and correctional facilities: a systematic review and meta regression analysis of 25 surveys. J Am Acad Child Adolesc Psychiatry 47:1010-1019

13. Foster EM, Jones DE (2005) The high costs of aggression: public expenditures resulting from conduct disorder. Am J Public Health 95:1767-1772

14. Gillberg C, Gillberg IC, Rasmussen P, Kadesjo B, Soderstrom H, Rastam M, Johnson M, Rothenberger A, Niklasson L (2004) Co-existing disorders in ADHsD-implications for diagnosis and intervention. Eur Child Adolesc Psychiatry 13(Suppl 1):I80 192

15. Gustavson C, Stahlberg O, Sjodin AK, Forsman A, Nilsson T, Anckarsater H (2007) Age at onset of substance abuse: a crucial covariate of psychopathic traits and aggression in adult offenders. Psychiatry Res 153:195-198

16. Hare RD (2003) The Hare psychopathy checklist—revised (2nd ed). Multi-Health Systems, Toronto

17. Hofvander B, Ossowski D, Lundstrom S, Anckarsater H (2009) Continuity of aggressive antisocial behavior from childhood to adulthood: the question of phenotype definition. Int $\mathrm{J}$ Law Psychiatry 32:224-234

18. Kadesjo B (2000) Neuropsychiatric and neurodevelopmental disorders in a young school-age population. Epidemiology and comorbidity in a school health perspective. Göteborg University, Göteborg

19. Kadesjo B, Gillberg C (2001) The comorbidity of ADHD in the general population of Swedish school-age children. J Child Psychol Psychiatry 42:487-492

20. Kadesjo B, Gillberg C, Hagberg B (1999) Brief report: autism and Asperger syndrome in seven-year-old children: a total population study. J Autism Dev Disord 29:327-331

21. Kim-Cohen J, Caspi A, Moffitt TE, Harrington H, Milne BJ, Poulton R (2003) Prior juvenile diagnoses in adults with mental disorder: developmental follow-back of a prospective-longitudinal cohort. Arch Gen Psychiatry 60:709-717
22. Luby JL, Svrakic DM, McCallum K, Przybeck TR, Cloninger CR (1999) The junior temperament and character inventory: preliminary validation of a child self-report measure. Psychol Rep 84:1127-1138

23. Meltzer H, Gatward R, Corbin T, Goodman R, Ford T (2003) The mental health of young people looked after by local authorities in England. The Stationery Office, London

24. Merikangas KR, He JP, Brody D, Fisher PW, Bourdon K, Koretz DS (2010) Prevalence and treatment of mental disorders among US children in the 2001-2004 NHANES. Pediatrics 125:75-81

25. Moffitt TE, Caspi A, Dickson N, Stanton W, Silva PA (1996) Childhood-onset versus adolescent-onset antisocial conduct problems in males. Dev Psychopathol 8:399-424

26. Nicol R, Stretch D, Whitney I, Jones K, Garfield P, Turner K, Stanion B (2000) Mental health needs and services for severely troubled and troubling young people including young offenders in an N.H.S. region. J Adolesc 23:243-261

27. SFS 1990:52 Swedish Codes of Statutes (1990) Care of Young Persons (special provisions) Act Department of Justice

28. SFS 1998:603 Swedish Codes of Statutes (1998) Care of Young Offenders Act Department of Justice

29. SFS 2001:453 Swedish Codes of Statutes (2001) The Social Services Act Department of Justice

30. Soderstrom H, Sjodin AK, Carlstedt A, Forsman A (2004) Adult psychopathic personality with childhood-onset hyperactivity and conduct disorder: a central problem constellation in forensic psychiatry. Psychiatry Res 121:271-280

31. Teplin LA, Abram KM, McClelland GM, Dulcan MK, Mericle AA (2002) Psychiatric disorders in youth in juvenile detention. Arch Gen Psychiatry 50:1133-1143

32. Timmons-Mitchell J, Brown C, Schulz SC, Webster SE, Underwood LA, Semple WE (1997) Comparing the mental health needs of female and male incarcerated juvenile delinquents. Behav Sci Law 15:195-202

33. Wechsler D (1991) Manual for the Wechsler Intelligence Scale for Children, 3rd edn. The Psychological Corporation, San Antonio

34. Wechsler D (1997) Wechsler Adult Intelligence Scale, 3rd edn. The Psychological Corporation, San Antonio 